\title{
Viewpoint
}

\section{Physician remuneration in industry-sponsored clinical trials: the case for standardized clinical trial budgets}

\author{
Lorraine E. Ferris, C. David Naylor
}

ß S See related articles pages 889 and 892

$\mathrm{P}$ hysicians who participate in clinical trials can contribute to the evidentiary base for practice and can offer their patients a chance to receive cutting-edge therapies and the close follow-up that often accompanies a trial protocol. As well, trial participation can benefit physicians themselves, through research opportunities for those holding faculty appointments and, where trials are sponsored by industry, a flow of income outside the public health insurance system.

Clinical trials are clearly an important industry: in 2002, Health Canada reported 1287 new clinical trial applications. ${ }^{1}$ We estimate that hundreds, if not thousands, of physicians across Canada are involved in these trials and have signed contracts with industrial sponsors in recent years.

What provisions do these contracts normally include? The sponsor of a clinical trial to test an investigational drug or device enters into agreements with collaborating physicians about intellectual property issues, the trial protocol and the financial arrangements for the physicians' provision of services to the study patients and to the sponsor. Health Canada, the federal authority that regulates pharmaceutical agents, through its adoption of the International Conference on Harmonisation guidelines, ${ }^{2}$ states that the official documentation must include a clinical trial budget that is kept on record by the study sites and the sponsor. Current Canadian legislation ${ }^{3,4}$ does not specify the level of budgetary detail and does not provide guidance as to what constitutes a reimbursable service or what would be considered reasonable reimbursement levels. Health Canada considers the review of clinical trial agreements and any related financial agreements as outside the scope of their inspection strategy for clinical trials.

The meaning of all this is simple: the information available to local administrators and research ethics boards (REBs) varies from one contract to the next, as do the arrangements for physician compensation. Even the agreements between individual physicians and the sponsor within the same clinical trial can be heterogeneous, since negotiated terms and conditions may vary by physician and by site.

Industry's role in innovation and research is important, but concern continues that investor-owned corporations must perforce tend to business interests, and these could ad- versely influence research and compromise its integrity. ${ }^{6-9}$ For individual physicians and sites, a partnership with industry may therefore create conflicts of interest, "a set of conditions in which professional judgment concerning a primary interest (e.g., a patient's welfare or the validity of research) tends to be unduly influenced by a secondary interest (e.g., financial gain). ${ }^{\prime 10}$ Actual conflicts of interest raise serious ethical concerns. ${ }^{1{ }^{112}}$ However, even absent direct conflicts of interest, the public's trust may be eroded by perceptions that industry's business interests are influencing or compromising clinical judgement and scientific integrity. ${ }^{13,14}$ Although we agree with the Kirby report that the "majority of industry works to high standards of ethics, fully consistent with the expectations of Canadians," ${ }^{15}$ as do physicians, the stakes are high and some oversight is surely appropriate for clinical trial contracts. A first step is to address what is reasonable and just remuneration for physicians involved in clinical trials.

\section{General principles for physician reimbursement}

The Canadian Medical Association Policy on Physicians and the Pharmaceutical Industry ${ }^{16}$ has reinforced the principle of "reasonable" physician remuneration (Table 1). However, it does not specify which services should be included or how reasonable levels of compensation can be set. The policy stresses the importance of oversight of remuneration by an approved board, agency or body (which has the authority to approve the use of human subjects). Although all studies involving human subjects must undergo REB review, such groups have to date received no guidance in the matter of remuneration. For example, REBs are guided by the TriCouncil Policy Statement, which offers only that "REBs shall examine the budgets of clinical trials to assure that ethical duties concerning conflict of interest are respected." ${ }^{19}$

One of the first needs, therefore, is for an informed debate to frame a consensus on parameters for reasonable remuneration for physicians participating in clinical trials. To start that debate, Table 2 shows a potential classification for physician remuneration in clinical trials and suggests possible standards for each group. 


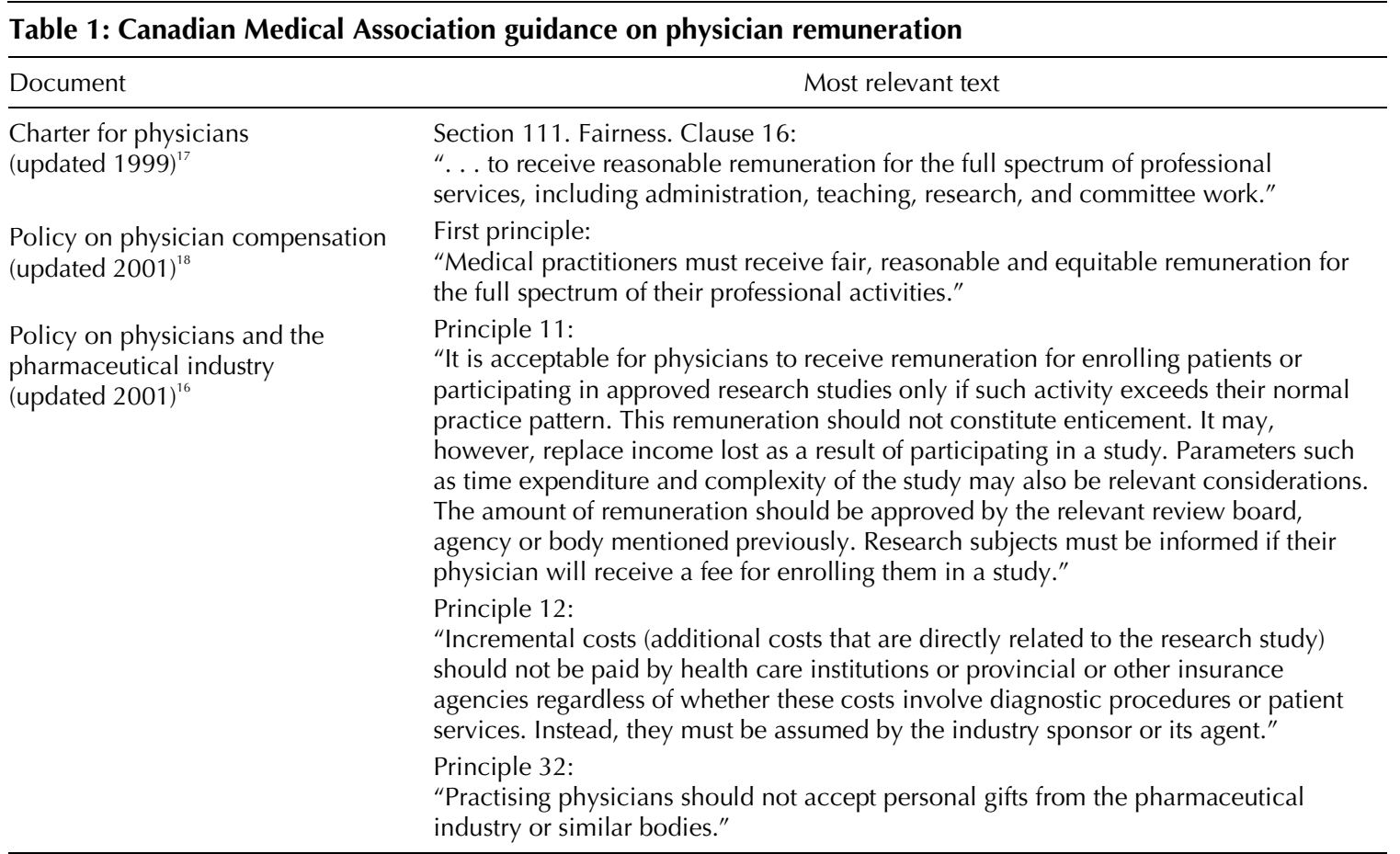

\section{Table 2: Categories and proposed standards for physician remuneration in a clinical trial}

\section{Activities and costs for which physicians should be remunerated \\ Patient care*}

Care beyond what patients would receive were they not in the trial or care not billable through the physician's payment mechanisms. Compensation should be in keeping with the allowable amounts within a respected and recognized payment plan that considers the type of care provided and the specialty of the physician.

Direct service to industry*

Face-to-face activities not suitable for remuneration as patient care, e.g., obtaining informed consent, interviewing patients or collecting study data. Compensation should be aligned with medical association rates in the jurisdiction where the physician practices.

Indirect service to industry*

Activities that do not involve face-to-face interaction with the patient and that are not suitable for remuneration as patient care, generally administrative activities including correspondence with the sponsor or others as required in the approved protocol, completion of adverse event reports and preparation of applications for research ethics boards. Compensation should be aligned with medical association rates in the jurisdiction where the physician practices.

Administrative costs

Including office supplies and administrative support for managing the trial. If costs involve reimbursement for administrative personnel, they should be in keeping with the individual's usual pay rate and the amount of time devoted to the trial.

Other costs

Costs for other professionals needed to conduct the trial (e.g., nursing staff). These professionals (or, if warranted, their institution) should be reimbursed at their usual pay rate and for the amount of time devoted to the trial. If these professionals are delegated to provide some of the direct or indirect services associated with the trial, the amount of physician remuneration should be reduced accordingly.

\section{Activities for which physicians should not be remunerated or otherwise rewarded}

Identifying or recruiting a patient, enrolling a particular number of patients or meeting a deadline in recruiting patients (i.e., finders' fees).

Completion of the study by a patient, completion of the study by a particular number of patients or completion of the trial within a specific timeframe (i.e., completion fees). ${ }^{20,21}$

Use of a name, endorsement of a clinical trial or any other activity likely to suggest bias to a reasonable observer.

*Physicians should receive remuneration for these activities regardless of whether services are provided to patients being considered for inclusion in the trial or to those that have been accepted into a trial. 


\section{Standardizing clinical trial budgets}

Agencies reviewing clinical trial applications at the institutional level (e.g., REBs) can assess potential conflicts of interest only if they see the clinical trial budgets something that does not always happen today. Those budgets must be organized in a uniform manner that reflects the agreed categories of remunerable service. Absent access to a template budget for clinical trials, REBs may have difficulty evaluating what services are being remunerated and at what rate. We therefore suggest the use of a standardized budget template for classifying the categories of physician remuneration, regardless of the type of trial or location. It is premature to provide "best practice" parameters for these categories, but progress toward a common method of reporting categories of remuneration should lead to improved sector-wide communication and allow some basic standards for clinical trial budgets to emerge rapidly. Standardized clinical trial budgets would be based on categories, definitions and standards such as those in Table 2. At a minimum, the unit cost per patient for each service rendered should be easily identifiable in the budget, making it possible to determine what services are offered and for what cost. We recognize that flexibility in the template is needed to accommodate different study types (e.g., phase II versus phase III, or single versus multicentre trials), but greater standardization is still possible and, in our view, desirable.

\section{Sharing of clinical trial budgets}

The uncertainty about current practices arises not just from the lack of detail in current budgets, but also from the fact that they are rarely shared across institutions. Only with disclosure and discussion can "best practices" emerge with respect to physician remuneration. In addition to reducing potential financial conflicts of interest and conforming to broad principles of transparency and accountability, disclosure will promote equity in physicians' clinical trial remuneration. We believe that institutions and physician-researchers should reject any industry contract that prohibits appropriate disclosure of information about the financial arrangements or that allows only conditional disclosure. Disclosure also extends to patients. As such, physicians and site administrators should include a statement in the trial consent form about reimbursement for physicians and others involved in running the trial.

Although our focus here is on physician payment, institutional remuneration must also be considered in the near future. Some institutions receive funds from industry for actually running or administering a trial (e.g., overhead charges), for simply agreeing to participate in the trial (e.g., donations to the institution for that decision) or for other trial-associated activities, including related research programs and clinical services. "Sunshine rules" for all financial aspects of clinical study agree- ments, similar to those suggested above for physician remuneration, would mitigate potential institutional conflicts of interest.

\section{Conclusions}

Financial conflict of interest is subjective and may never be completely avoided. However, no one wants to see patterns of physician remuneration that could be interpreted as a threat to scientific integrity or good clinical judgement. Numerous editorials and empirical studies have examined conflict of interest, ${ }^{22,23}$ and there is a consensus that some physician payments should be banned (e.g., finders' fees and completion fees). However, there has been surprisingly little debate about clinical trial budgets in general and reasonable physician remuneration. In this brief commentary, we have urged standardization of categories of remunerable services, agreement on how physician payment levels should be set and transparency regarding the budgetary provisions in clinical trial agreements. These initial steps would help physicians and those who manage their practice sites to address perceived, potential or actual financial conflicts of interest in clinical research.

From the Faculty of Medicine, University of Toronto, Toronto, Ont. (Ferris and Naylor); and the Clinical Epidemiology Unit, Sunnybrook and Women's College Health Sciences Centre, Toronto, Ont. (Ferris)

Competing interests: None declared.

Contributors: Lorraine Ferris and David Naylor conceptualized the content of the article and its direction. Lorraine Ferris wrote the initial draft of the paper and approved the final version. David Naylor revised the draft and approved the final version.

\section{References}

1. Annual drug submission performance report - Part 1. Therapeutic Products Directorate (TPD) 2002. Ottawa: Health Canada; 2003 Mar. Available: www.hc-sc .gc.ca/hpfb-dgpsa/tpd-dpt/tpd_annual02_e.pdf (accessed 2004 Sep 8).

2. International Conference on Harmonisation (ICH) of Technical Requirements for Registration of Pharmaceuticals for Human Use. ICH harmonised tripartite guideline. Guideline for good clinical practice (E6). Geneva: ICH Secretariat; 1996. Available: www.ich.org/MediaServer.jser?@_ID=482\&@_MODE $=$ GLB $($ accessed 2004 Sep 8).

3. Food and Drugs Act, R.S.C. 1985, c.F-27, s.30(1)(1.1), as am. by S.C. 1999, c. 33, s. 347

4. Food and Drug Regulations Amendment (Schedule No. 1024) Clinical Trial Framework, SOR/2001-203.

5. Health Canada's response to letter from L. Ferris and D. Naylor regarding inspection strategy for clinical trials involving human subjects [response ref no. 02 121179-994, dated 2003 Feb 21]. Available: www.library.utoronto.ca/medicine /medUT/lettresp.pdf (accessed 2004 Sep 9). Letter to Health Canada also available online at: www.library.utoronto.ca/medicine/medUT/hcletter.pdf (accessed 2004 Sept. 09).

6. Korn D. Conflicts of interest in biomedical research. 7AMA 2002;284:2234-7.

7. Bodenheimer T. Uneasy alliance: clinical investigators and the pharmaceutical industry. N Engl 7 Med 2002;342:1539-44.

8. Lexchin J, Bero LA, Djulbegovic B, Clark O. Pharmaceutical industry sponsorship and research outcome and quality: systematic review. BM7 2003; 326(7400):1167-70.

9. Bekelman JE, Li Y, Gross CP. Scope and impact of financial conflicts of in terest in biomedical research: a systematic review. FAMA 2003;289:454-65.

10. Thompson DF. Understanding financial conflicts of interest. $N$ Engl $7 \mathrm{Med}$ 1993;329:573-6.

11. DeRenzo EG. Coercion in the recruitment and retention of human research subjects, pharmaceutical industry payments to physician-investigators, and the moral courage of the IRB. IRB 2000;22(2):1-5. 
12. Association of American Medical Colleges, Task Force on Financial Conflicts of Interest in Clinical Research. Protecting subjects, preserving trust, promoting progress - policy and guidelines for the oversight of individual financial interests in buman subjects research. Washington (DC): The Association; 2001. Available: www.aamc.org/members/coitf/firstreport.pdf (accessed 2004 Sep 8).

13. DeAngelis CD. Conflict of interest and the public trust [editorial]. $7 A M A$ 2000;284:2237-8

14. The controlling interests of research [editorial]. CMA7 2002;167(11):1221.

15. Section 12.7.6. Potential situations of conflict of interest. In: Kirby MJL chair. The health of Canadians - the federal role. Vol 6: Recommendations for Reform. Ottawa: Standing Senate Committee on Social Affairs, Science and Technology; 2002.

16. CMA policy: physicians and the pharmaceutical industry (update 2001). Ottawa: Canadian Medical Association; 2001. Available: www.cma.ca//multimedia/static Content/HTML/N0/12/where_we_stand/physicians_and_the_pharmaceutical industry.pdf (accessed 2004 Sep 1).

17. CMA charter for physicians (update 1999). Ottawa: Canadian Medical Association; 1999. Available www.cma.ca/index.cfm/ci_id/3048/la_id/1.htm (accessed 2004 Sep 1).

18. CMA policy: physician compensation (update 2001). Ottawa: Canadian Medical Association; 2001. Available: www.cma.ca/multimedia/staticContent /HTML/N0/12/where_we_stand/physician_compensation.pdf (accessed 2004 Sep 1).
19. Tri-Council policy statement: ethical conduct for research involving bumans. Ottawa: Medical Research Council of Canada; Natural Sciences and Engineering Research Council of Canada; Social Sciences and Humanities Research Council/pdf/TCPS\%20June2003_E.pdf (accessed 2004 Sep 8).

20. Policy on the offer and acceptance of finders' fees or completion fees in research involving human subjects. Toronto: University of Toronto, Faculty of Medicine; 2003 Mar. Available: http://eir.library.utoronto.ca/medicine/calendar /reg_offer.cfm

21. Coyle SL; Ethics and Human Rights Committee, American College of Physicians-American Society of Internal Medicine. Physician-industry relations. Part 1: individual physicians. Ann Intern Med 2002;136:396-402.

22. Kelch RP. Maintaining the public trust in clinical research. $N$ Engl 7 Med 2002:346:285-7.

23. Smith R. Maintaining the integrity of the scientific record [editorial]. $B M 7$ 2001;323:588

Correspondence to: Dr. Lorraine E. Ferris, Department of Public Health Sciences, McMurrich Building, 12 Queen's Park Cres. W, 4th flr. Toronto ON M5S 1A8; fax 416 480-6048;

lorraine.ferris@utoronto.ca

\section{Canadian Medical Association}

\author{
2005 Special Awards - Call for Nominations
}

The Canadian Medical Association invites nominations for the 2005 special awards.

- Medal of Honour

- F.N.G. Starr Award

- Medal of Service

- May Cohen Award for Women Mentors

- Sir Charles Tupper Award for Political Action

- Award for Excellence in Health Promotion

- CMA Award for Young Leaders

Refer to the "Awards from CMA" section on cma.ca for detailed criteria on each of the awards or contact the awards co-ordinator at $1800663-7336$, ext. 2280.

Nominations should be submitted to:

Chair, Committee on Archives

c/o Committee Co-ordinator

Strategic and Corporate Affairs

Canadian Medical Association

1867 Alta Vista Drive

Ottawa, ON K1G 3 Y6

Closing date for receipt of nominations is Nov. 30, 2004.

\section{Association médicale canadienne}

Prix spéciaux pour l'an 2005 - Appel de candidatures
L'Association médicale canadienne sollicite des candidatures à ses prix spéciaux pour l'an 2005.

- Médaille d'honneur

- Prix F.N.G. Starr

- Médaille de service

- Prix May-Cohen pour femmes mentors

- Prix Sir-Charles-Tupper d'action politique

- Prix d'excellence de l'AMC en promotion de la santé

- Prix des jeunes chefs de file de l'AMC

Voir «Prix et distinctions de l'AMC» sur le site amc.ca pour les critères détaillés de chaque prix ou contacter la coordonnatrice des prix au 1800 663-7336, poste 2280 .

Les candidatures doivent être soumises au :

Président, Comité des archives a/s Coordonnatrice des comités Affaires générale et Stratégiques Association médicale canadienne 1867, promenade Alta Vista Ottawa (Ontario) K1G 3 Y6

Les candidatures doivent être présentées au plus tard le 30 novembre 2004. 